\title{
A comparative study of trouser pattern making methods
}

\begin{abstract}
The rate of wearing trousers by females has increased in our modern society, and increasing demands for trousers are not only for functional aspects but also aesthetic aspects, physical suitability and movement adaptability. Fit is one of the major concerns for the clothing industry, and pattern development process is significant during clothing manufacturing and the way clothing is constructed. Various pattern making methods have been introduced to the industry considering clothing fit satisfaction, but it is still impossible to provide the optimized clothing pattern for mass production. This study evaluated four trouser pattern making methods known as the Aldrich, Armstrong, Bunka, and ESMOD methods focusing on fit consideration by application onto human subject's evaluation test. The fundamental body dimension data were measured by a 3D body scanning system, and four trousers according to the four different methods were produced by both manual methods and an apparel CAD programme. The developed trouser pattern blocks were compared using each part of constructing formula and actual sizes. Experimental trousers were evaluated by expert and subject using questionnaires, focus group, and in-depth interview. The result of evaluation was analysed by statistical and qualitative analysis.
\end{abstract}

Keywords: clothing fit, clothing comfort, fit evaluation, fit preference, trousers pattern
Volume I Issue 5 - 2017

\author{
Hye-Won Lim, Tom Cassidy
}

University of Leeds, UK

Correspondence: Hye-Won Lim, School of Design, University of Leeds, UK, Tel 4474802I3635, Email sdI0hwl@leeds.ac.uk

Received: February 16, 2017 | Published: May 04, 2017

\section{Introduction}

The clothing industry has been developing under the influence of customers' growing needs and machine development. One of the aspects of competitiveness in the clothing industry is to have professional pattern making skills to fit customers' satisfaction. Therefore, various pattern making methods have been introduced to define the clothing fit and suitable size for different body shapes and body measurements.

The pattern for clothing is a set of two-dimensional template pieces for a basic three-dimensional garment, and it is also called a block, a sloper, or a master pattern. ${ }^{1}$ A clothing pattern is required to adapt to the characteristic of body size and body type, and it is classified into basic block pattern, style block pattern, and production pattern. The basic block pattern is the pattern which is constructed from body measurements with affordable ease allowance for movability. The style block pattern is the clothing pattern which has a specific style of basic design, and the production pattern is the final developed pattern for manufacturing different clothing sizes. ${ }^{2,3}$

The basic block pattern is important because it is the basis to be modified for developing further stages of the pattern. The ideal basic block pattern is required to cover various body types and to apply any design and clothing type. ${ }^{2}$ Also, a basic block pattern is developed for efficient clothing manufacturing production. ${ }^{4}$ The purpose of any basic block pattern is to provide:
a. Consistent fit
b. Appropriate ease
c. A source for styled patterns
d. A reference for obtaining other sizes in the range

e. A reduction in the number of patterns to be retained and stored and

f. Streamlined product development of each succeeding seasonal line. ${ }^{5}$

Pattern makers convert the basic block pattern into the more detailed design. When pattern makers develop a clothing pattern, fit evaluation is carried out to check for problems before clothing manufacturing. The clothing industry normally uses fitting models or dress forms to confirm design and fit. Using fitting models is determined as one of the best fit examination methods because it helps to observe closely and to inspect movements properly. ${ }^{6}$

Clothing fit analysis is a complicated process to find out the relation between the body and clothing, and to judge how much the clothing has to be adjusted to a set of requirements. ${ }^{7}$ There are five elements in clothing fit evaluation; ease, line, grain, balance, and set. ${ }^{7}$ Well-fitted garments should sit properly on the body having proper proportions and sufficient ease without pulling, fabric contortions, and compression. Consideration of customer fit preference is crucial for the clothing manufacturing process, and clothing manufacturers should analyze the body size and type of the target market even though each customer's preference might be subjective and different. ${ }^{8}$

The experimental fit evaluation is divided into a sensory test and a $3 \mathrm{D}$ non-contact test. A sensory test is conducted by the subjective judgments of experts or wearers. A sensory evaluation is a method using the psychological premise to judge physical properties and to predict customers' reactions. ${ }^{9}$ Also, a sensory test allows for systematic subjective product evaluation and it is a professional and expert judge's responses. ${ }^{8,9}$ There are some limitations which surround circumstance and personal situation influencing the accuracy of the inspection because this test relies only on human visual sense. Also, 
there is a limitation that examiners might have different understanding or feeling of the same descriptive terms. However, human judgment according to the affordable amount of sensory variation is generally accepted. Sensory tests are classified into an appearance evaluation of the experimental garments, and subjective wearing sensation measurements by wearers. A checklist is constructed using photographs or illustration of garments and a Likert scale survey question at the sensory test. A 3D non-contact test which uses virtual garment simulation allows checking virtual images of wearers on the computer screen. This test helps to measure the gap between body and garment providing objectively quantifiable data. Even though a $3 \mathrm{D}$ non-contact test in the clothing industry is not yet generally used, it is evident that this method allows saving time and cost of clothing manufacturing process. ${ }^{10}$

The frequency of female consumers wearing trousers has shown a big increase compared to skirts in modern society. ${ }^{11}$ Trousers are defined as 'an outer garment covering the body from the waist to the ankles, with a separate part for each leg', and the stitch line is passed by front and back crotch line. ${ }^{12,13}$ Trousers are more likely to show considerable body shape, and movement suitability is more required than skirts, and trouser pattern development needs more body dimension data than skirts. ${ }^{14}$ Trousers pattern development is influenced by body shape differences according to muscles and degree of physical development, amount of subcutaneous fat and distribution as well as increases with age. Increasing of the waist and hip circumference and depth measurements followed by physical developments is mainly considered for trouser development. Also, thigh fat distribution and hip laxity are significant issues for developing trouser patterns. ${ }^{14}$

Trouser patterns from basic to final have been studied focused on different ages, body shapes, and fabrics. As to basic trouser pattern development, Kim ${ }^{15}$ has classified lower body type of obese senior women by the Rohrer index, then the experimental pattern block and trousers for six different types of subjects were evaluated. Hwang ${ }^{16}$ focused on abdominal obese body type women selected from the national sizing survey. Trouser basic pattern blocks were developed based on the classified four groups having different influential factors. Lee JS \& Lee JR ${ }^{17}$ chose five obese women in their twenties and thirties based on BMI, and five different pattern making methods were tested, and Lee DY ${ }^{18}$ selected subjects who had a greater hip circumference and depth than the average women in their twenties, and three different pattern making methods were tested. Regarding different fabrics, trouser pattern for the plus-sized women in their twenties made by jeans was examined by Byun. ${ }^{19} \mathrm{Knitted}$ trousers for middle-aged women were developed by Lee $\mathrm{JJ},{ }^{20}$ and she found that the front and back crotch length and crotch width should be longer for specific comfort with age.

In this study, the aims are to evaluate four different trouser pattern making methods with a focus on a specific body shape, and to find the most appropriate method. The characteristics of each pattern making methods were compared, and the fit evaluation of experimental trousers was conducted by experts and the subject.

\section{Materials and methods}

\section{Sources of pattern making methods}

Four pattern making books were selected due to their prominence and popularity in different countries. ${ }^{13,14,21,22}$ In this study, each method was named as 'Aldrich', 'Armstrong', 'Bunka', and 'ESMOD'. The selected books were written in English except for the Bunka method which was translated into Korean. All methods use the metric system except the Armstrong method, and imperial system of the Armstrong method was converted into the metric system.

\section{Subject selection}

The subject of this study was recruited from design students at the University of Leeds. One Korean female subject aged 29 was selected by the purposive sampling method because she had physically developed body features especially greater hip size than average in her country, and this will be described at the subject' classification in the next section. This distinctive physical difference and difficulties in buying comfortable fit of trousers of subject were influenced for the subject selection.

\section{Body dimensions measurement}

Body sizes of the selected subject were measured by a 3D body scanning system and manual measuring tools. Height, weight, girths of hand and head were measured by an anthropometer, a weight scale and a tape measure. A $[\mathrm{TC}]^{2} 3 \mathrm{D}$ body scanner was used to measure the other body sizes. The subject was required to wear skin coloured upper and lower underwear during the scanning process. Figure 1 shows the 3D scanned data of the subject.

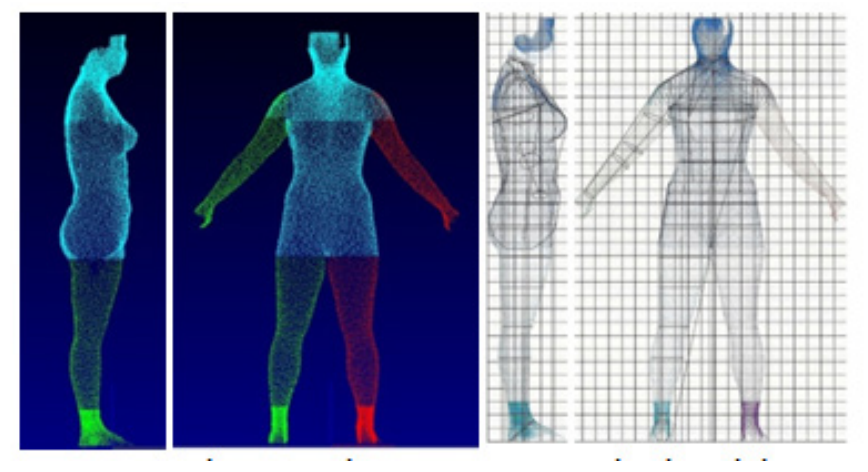

Figure I Body scans data on screen and printed data.

\section{Subject classification}

BMI is body mass index which is calculated by Weight $(\mathrm{kg}) /$ Height $(\mathrm{m})^{2}$. According to the NHS in the UK, the BMI of the subject $(167.7 \mathrm{~cm}$ and $68 \mathrm{~kg})$ was calculated as 24.1 , and is considered healthy (normal) weight. ${ }^{23}$ However, this BMI value of 24.1 is classified as 'overweight' in Korea. Size Korea describes that BMI under 18.5 is low weight, 18.5 22.9 is normal weight, 23 24.9 is overweight, $25 \sim 30$ is moderate obesity, and over 30 is high-risk obesity. ${ }^{24}$ As can be seen in Figure 2, the height and weight of the subject are ranked at the $98 \%$ and $95 \%$ respectively among the age group.

Regarding Size Korea classification, Korean females in their 20 's are divided into four body types; small inverted triangle, large inverted triangle, inverted triangle, and rectangle. ${ }^{24}$ According to the results of 'Female figure identification technique (FFIT) for apparel ${ }^{\odot}$ ' division, the subject has an hourglass body shape because there is a small difference between her bust and hip and the ratios of bustwaist and hip-waist are almost equal. ${ }^{25}$ Therefore, it is found that the selected subject does not belong to Size Korea's classification, and the each measurement is greater than the average Korean female Table 1. 
Table I Size Korea's body type classification and subject's body measurement $(\mathrm{cm})$

\begin{tabular}{|c|c|c|c|c|c|c|}
\hline & Small inverted triangle & $\begin{array}{l}\text { Large inverted } \\
\text { triangle }\end{array}$ & $\begin{array}{l}\text { Inverted } \\
\text { triangle }\end{array}$ & Rectangle & Average & Subject \\
\hline Proportion & $29.00 \%$ & $17.30 \%$ & $28.80 \%$ & $25.00 \%$ & - & - \\
\hline Bust & 80 & 90.6 & 81.7 & 80.7 & 83.4 & 100.7 \\
\hline Waist & 65.5 & 76.2 & 67.2 & 65.9 & 67.5 & 75.9 \\
\hline Hip & 89.1 & 95.6 & 91.4 & 90.1 & 91.6 & 101.9 \\
\hline Hip-Bust & 9.1 & 5 & 9.7 & 9.4 & 8.2 & 1.2 \\
\hline Bust-Waist & 14.5 & 14.4 & 14.5 & 14.8 & 15.9 & 24.8 \\
\hline Hip-Waist & 23.6 & 19.4 & 24.2 & 24.2 & 24.1 & 26 \\
\hline
\end{tabular}

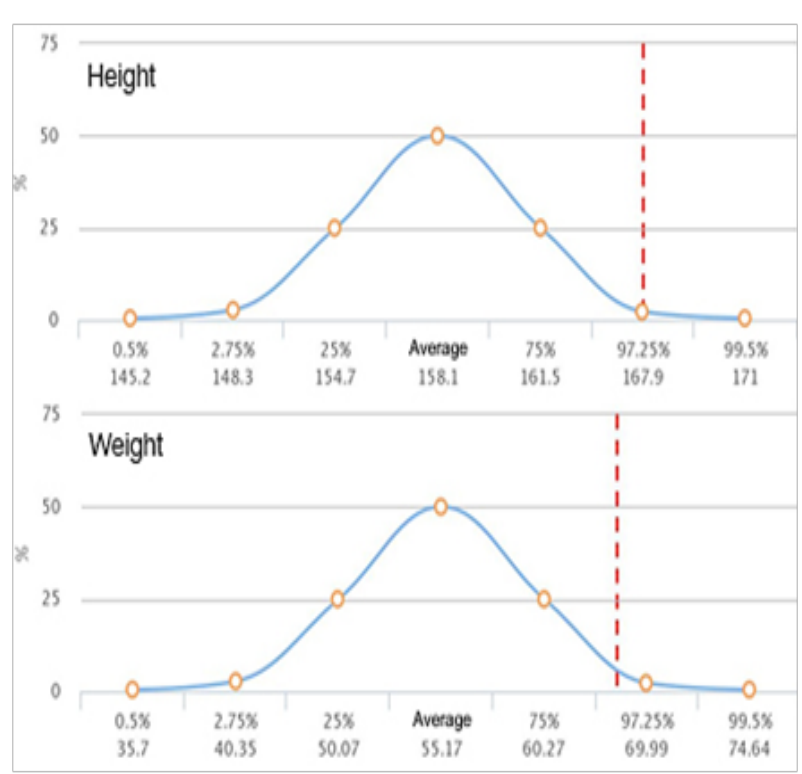

Figure 2 Distribution of selected subject.

\section{Fundamental body measurement sizes}

The fundamental body sizes for trouser pattern development were collected from all measured body sizes Table 2 .

Table 2 Major body sizes of subject for trousers pattern development

\begin{tabular}{ll}
\hline Part & Size \\
\hline Waist (Front) circumference & $75.9 \mathrm{~cm}$ \\
Hip circumference & $101.9 \mathrm{~cm}$ \\
Hip length (Right side waist to hip) & $22.3 \mathrm{~cm}$ \\
Total crotch length & $68.3 \mathrm{~cm}$ \\
Outside leg length & $98.6 \mathrm{~cm}$
\end{tabular}

\section{Experimental trousers pattern development}

Trouser patterns according to selected four pattern making methods were made in the YUKA apparel CAD system (Super ALPHA: Plus). The functions of this apparel CAD program are mainly pattern making, grading, and marking, but only the pattern making tool was used to make the trouser pattern, and all pattern data were saved in a DXF file format.

\section{Experimental trousers development}

$100 \%$ cotton muslin was used to make the experimental garments. Table 3 shows the fabric mechanical property values measured by KES (Kawabata Evaluation System). In this study, A KES-FB-AUTO-A system (KATO TECH) machine was used and the environment of the test was $20 \pm 2^{\circ} \mathrm{C}$ (temperature) and $65 \pm 2 \%$ (humidity).

The experimental trousers were developed by a garment making specialist followed by a bespoke sample making process. $1 \mathrm{~cm}$ of the seam was used and a concealed zipper was attached at the side seam.

\section{Experimental trousers photograph shooting}

The subject with the experimental trousers stood straight, and photographs of the front, side, and back were taken. Additional postures of 'stepping at walking pace', 'sitting $90^{\circ}$ ', 'stooping $90^{\circ}$,' 'climbing the stairs', and 'squatting on hams' numbered from Movement 1 to Movement 5 were followed Figure 3.

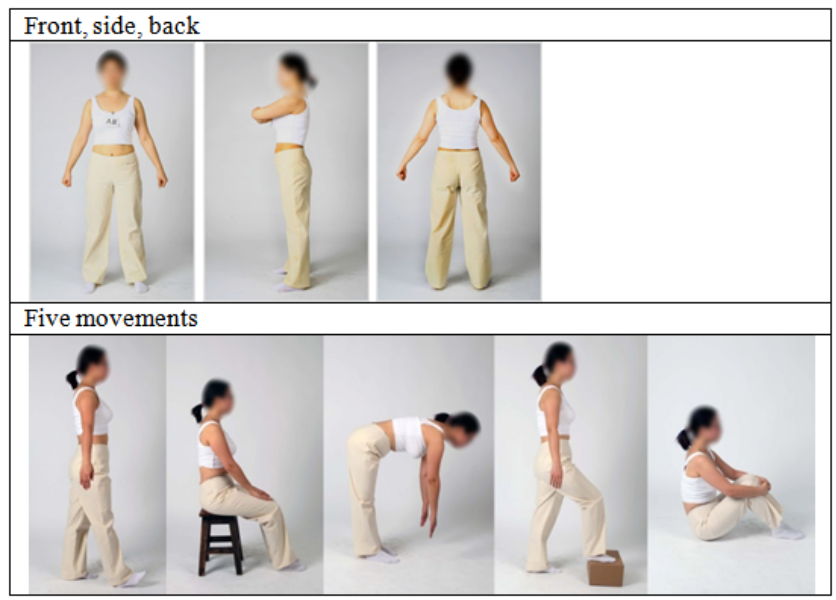

Figure 3 Upright postures and five movements for evaluation.

\section{Evaluation of experimental trousers}

Appearance and fit suitability examination was conducted by 18 pattern making experts. These consisted of fashion majored MA and $\mathrm{PhD}$ students and university teaching staff in the UK and Korea. The evaluation was carried out according to specific criteria on each part of the body; (1) Front, (2) Side, and (3) back Table 4. The experts observed photographs of the subjects, and five-point scale rating methods were used for response scores; 'very good $=5$ ', ' $\operatorname{good}=4$ ', 'neutral $=3$ ', 'bad $=2$ ', 'very bad $=1$ '. The subject also evaluated the 
experimental trousers when she changed the postures using the same criteria of the experts while photographs were taken. As for the deeper understanding of the experimental trousers, discussions were held with experts and subject.

\section{Analysis of experimental trousers}

Comparison of the fundamental composition of the four pattern making methods was conducted. The construction of the major body measurement parts with ease allowance was compared including position, amount, and length of darts. Also, crotch length, depth, and Table 3 Mechanical property values of experimental fabric extension amounts were also compared. The calculation formula of each measurement and actual size after following pattern development were also used for the comparison.

As to the evaluation, quantitative data was analysed. The mean and standard deviation were calculated to measure the highest rank and variance analysis were conducted to verify significant differences in each body part and pattern making method. The narrative discussion of the focus group and interview were recorded, and these were analysed by qualitative analysis.

\begin{tabular}{|c|c|c|c|c|c|c|c|c|c|}
\hline \multirow[t]{2}{*}{ Fabric } & \multirow{2}{*}{$\begin{array}{l}\text { Tension (8) } \\
\text { Warp }\end{array}$} & \multicolumn{3}{|c|}{$\begin{array}{l}\text { Bending } \\
\mathrm{B}\left(\mathrm{g} \cdot \mathrm{cm}^{2} / \mathrm{cm}\right) 2 \mathrm{HB}(\mathrm{g} \cdot \mathrm{cm} / \mathrm{cm})\end{array}$} & \multirow[b]{2}{*}{ Weft } & \multicolumn{2}{|c|}{$\begin{array}{l}\text { Shear } G(\mathrm{~g} / \mathrm{cm} \text { deg }) \\
2 \mathrm{HG}(\mathrm{g} / \mathrm{cm})\end{array}$} & \multirow[t]{2}{*}{$\begin{array}{l}\text { Weight } \\
\left(\mathrm{mg} / \mathrm{cm}^{2}\right)\end{array}$} & \multirow[t]{2}{*}{$\begin{array}{l}\text { Thickness } \\
(\mathrm{mm})\end{array}$} \\
\hline & & Weft & & Warp & & & & & \\
\hline \multirow[t]{2}{*}{ Cotton $100 \%$} & 8.22 & 15.5 & B & 0.031 & 0.03 & G & 0.55 & 4.27 & 0.45 \\
\hline & & & $2 \mathrm{HB}$ & 0.0189 & 0.0206 & $2 \mathrm{HG}$ & 1.58 & & \\
\hline
\end{tabular}

Table 4 Experimental trousers' evaluation criteria

\begin{tabular}{lll}
\hline Part & S. no. & Criteria \\
\hline (1) Front & I & Length of dart \\
(3) Back & 2 & Position of dart \\
& 3 & Gap between darts \\
& 4 & Position of waistline \\
& 5 & Sufficient ease across Waist \\
& 6 & Sufficient ease across Abdomen \\
& 7 & Sufficient ease across Hip \\
& 8 & Sufficient ease across Crotch \\
& 9 & Sufficient ease across Thigh \\
& 10 & Crotch line is free from pulling or riding \\
& I & Balance between front and back sides \\
& 2 & Side seams appear as straight lines on the body \\
& 3 & Presence of wrinkles radiating in waist line \\
4 & & Presence of wrinkles radiating in hip line
\end{tabular}

\section{Results and discussion}

\section{Comparison of pattern making methods}

Major body measurements for trousers pattern developments are circumferences of waist and hip, and lengths of hip and crotch. Also, the amount and position of darts were influenced by the general shape and comfort ability of trousers.

As can be seen in Table 5, all the pattern making methods provide a different amount of allowances at waist and hip, and position and amount of darts were also different. The extra allowance of waist and hip were generated from the volume of overhanging parts on the front and back and influences the suitability of movement. As to the added amount of waist and hip, the Armstrong method adds the greatest amounts $(8.88 \mathrm{~cm}$ in the waist and $6.34 \mathrm{~cm}$ in hip).

Darts in trousers are positioned at the parts where have the longest distance between waist circumference and outside circumference of

the garment. In this study, the dart of the front waist was positioned at the front centre line except for the Bunka method which is located in the middle of the centre line and outseams line. Back waist darts of the Bunka and ESMOD methods were located in the middle of the back waistline, and two back waist darts of Aldrich were positioned at the point of $1 / 3$ back waistline but the Armstrong method follows the specific amount of guideline $(7.62 \mathrm{~cm}$ and $3.17 \mathrm{~cm})$.

Hip length and Crotch area construction: Hip length is the length from lateral waist to buttock protrusion on the right side of the body, and it is measured following the body surface line ${ }^{24}$ Figure 4. Hip length is determined in proportion to height (Height/12), and it is also suggested with a fixed dimension $(18 \mathrm{~cm}){ }^{26}$ The measured hip length of the subject is $22.3 \mathrm{~cm}$, and this dimension is longer than the hip length of Aldrich and Armstrong methods. Therefore, it is concluded that the suggested hip lengths of Aldrich and Armstrong are not sufficient for the subject. The crotch is defined as "The part of the human body between the legs where they join the torso." ${ }^{12}$ Crotch length is measured from the point of anterior waist to posterior waist passing crotch point, but body rise is the vertical distance from the waistline to crotch point ${ }^{24}$ Figure 4 . In this study, Aldrich method uses body rise $(25.3 \mathrm{~cm})$ while other methods use crotch length to define the level of crotch depth line. Armstrong and ESMOD methods suggest choosing the crotch size to be matched the subjects' garment sizes in their own guides, and Bunka method uses the actual crotch dimension Table 6.

Crotch length is also estimated from the hip circumference with movability allowance $(\mathrm{H} / 4+2 \sim 3 \mathrm{~cm})$, and the crotch of the selected subject is calculated $27.5 \sim 28.5 \mathrm{~cm} .{ }^{26,27}$ Therefore, it is found that Aldrich and ESMOD methods use shorter crotch length. Crotch extension is crucial for the aesthetic and functional part of trousers which decide the general appearance and comfort ability. As to crotch extension, ESMOD provides the shortest amount of crotch extension both front and back. It is concluded that ESMOD trousers have the tight crotch than other methods. Dropped amounts of back crotch point influences to wearers feel tighter, and four chosen methods have dropped back crotch amounts between $0.5 \sim 1 \mathrm{~cm}$ except Armstrong methods. Only Bunka method raises $1.2 \mathrm{~cm}$ at the side seam of the waist which influences the general waistline to make higher Table 6 .

Amount and length of darts: The amount of darts is usually calcu- 
lated by the difference between waist and hip circumferences, and length of the dart is decided by the protruded degree of abdomen area and shape of the hip. As can be seen in Table 7, Armstrong method uses the greatest amount of darts, the longest front dart length, and the shortest back dart length. The number of front darts Aldrich and Armstrong are two while Bunka and ESMOD have one, and a number of the back dart of all methods is one except two of Armstrong.

Width of trousers: The length of knee defines the position of the Table 5 Main part of trousers construction methods $(\mathrm{cm})$ knee which affects the leg length looks longer, and ESMOD was set at the highest position $(60 \mathrm{~cm})$. As to widths of knee and hem, the back width of four methods is wider than the front, and Bunka method has the widest knee and hem widths. It was also found that Aldrich and ESMOD provide the specifically added amount of back $(2 \mathrm{~cm}$ and 4 $\mathrm{cm}$ respectively) Table 8 . However, the width of knee and hem can be altered if it is necessary depending on design and style, and same amounts can be added or subtracted from the outline.

\begin{tabular}{llllll}
\hline Part & & Aldrich & Armstrong & Bunka & ESMOD \\
\hline Waist & Front & $\mathrm{W} / 4+2.25$ & $\mathrm{~W} / 4+3.17$ & $(\mathrm{~W}+\mathrm{I}) / 4+2$ & $\mathrm{~W}+2 / 4$ \\
& Back & $\mathrm{W} / 4+4.25$ & $\mathrm{~W} / 4+5.7 \mathrm{I}$ & $(\mathrm{W}+\mathrm{I}) / 4-2$ & $\mathrm{~W}($ Front $)+\mathrm{I}$ \\
Hip & Front & $\mathrm{H} / 4+0.5$ & $\mathrm{H}($ Front $) / 2+5.7 \mathrm{I}$ & $\mathrm{H} / 4+2$ & $\mathrm{H}+2 / 4$ \\
& Back & $\mathrm{H} / 4+\mathrm{I} .5$ & $\mathrm{H}($ Back)/2+0.63 & $\mathrm{H} / 4+0.5$ & $\mathrm{H}($ Front)+l.5 \\
$\begin{array}{l}\text { Position of } \\
\text { darts }\end{array}$ & Front & $\begin{array}{l}\text { Front centre } \\
\text { line }\end{array}$ & $\begin{array}{l}\text { Front centre line, } \\
3.17 \text { from the first dart }\end{array}$ & $\begin{array}{l}\text { Front centre line to out } \\
\text { seam } / 2\end{array}$ & $\begin{array}{l}\text { Front centre } \\
\text { line }\end{array}$ \\
& & & $\begin{array}{l}7.62 \text { from Back centre line, 3.17 from the } \\
\text { first dart }\end{array}$ & Waist (Back)/2 & Waist (Back)/2 \\
\hline
\end{tabular}

Table 6 Hip length and crotch construction in four pattern making methods $(\mathrm{cm})$

\begin{tabular}{lllllll}
\hline & $\begin{array}{l}\text { Hip } \\
\text { length }\end{array}$ & $\begin{array}{l}\text { Crotch } \\
\text { length }\end{array}$ & \multicolumn{2}{l}{ Crotch extension } & $\begin{array}{l}\text { Dropped amounts of } \\
\text { back crotch point }\end{array}$ & $\begin{array}{l}\text { Raised amounts of side } \\
\text { waist }\end{array}$ \\
\cline { 3 - 5 } & 21 & 29 & 6.8 & 12.8 & 0.5 & 0 \\
Aldrich & 21 & Front & Back & 0 & 0 \\
Armstrong & 18.6 & 27.9 & 6.4 & 13.2 & 0.6 & 1.2 \\
Bunka & 23.8 & 34 & 5.3 & 11.2 & 1 & 0 \\
ESMOD & 23.8 & 26.5 & 4.8 & 9.3 & 1 & 0 \\
\hline
\end{tabular}

Table 7 Darts construction in four pattern making methods

\begin{tabular}{lllllll}
\hline & Number & \multicolumn{3}{c}{ Amount } & Length \\
\cline { 2 - 7 } & Front & Back & Front & Back & Front & Back \\
\hline Aldrich & 2 & 1 & $2 \mathrm{~cm}$ & $4 \mathrm{~cm}$ & $10 \mathrm{~cm}$ & $12 / 10 \mathrm{~cm}$ \\
Armstrong & 2 & 2 & $2.54 \mathrm{~cm}$ & $5.08 \mathrm{~cm}$ & $11.43 \mathrm{~cm}$ & $7.62 \mathrm{~cm}$ \\
Bunka & 1 & 1 & $2.7 \mathrm{~cm}$ & $3.1 \mathrm{~cm}$ & $9 \mathrm{~cm}$ & $10 \mathrm{~cm}$ \\
ESMOD & $\mathrm{I}$ & $\mathrm{I}$ & $2.4 \mathrm{~cm}$ & $2.4 \mathrm{~cm}$ & $9 \mathrm{~cm}$ & $10 \mathrm{~cm}$
\end{tabular}

Table 8 Knee and hem construction in four pattern making methods $(\mathrm{cm})$

\begin{tabular}{llllll}
\hline \multirow{2}{*}{ Knee length } & \multicolumn{2}{l}{ Knee width } & Hem width \\
\cline { 3 - 6 } & & Front & Back & Front & Back \\
\hline Aldrich & 64.5 & 25 & 27 (Front width $+2 \mathrm{~cm})$ & 21.7 & 23.7 (Front width+2cm) \\
Armstrong & 66.4 & 25.4 & 30.5 & 20.3 & 22.8 \\
Bunka & 64.5 & 30 & 33 & 25.9 & 28.9 \\
ESMOD & 60 & 24 & 28 (Front width $+4 \mathrm{~cm})$ & 22 & 26 (Front width $+4 \mathrm{~cm})$ \\
\hline
\end{tabular}

\section{Appearance and fit evaluation}

Experts evaluation: The results of appearance and fit examination using by experts were analyzed by variance analysis, and the results were verified by Duncan's multiple tests $(A>B>C)$ Table 9 . Each part of the body (front, side, back) was analyzed separately, and the Ar- mstrong method was found as the most suitable at front and side with the back of the Aldrich method. When the movement was analyzed, the Aldrich method received the highest response for movements 2, 3, and 4, and ESMOD and Bunka were chosen for movement 1 and 5 respectively. Kendall's coefficient of concordance verified the level 
of significance the rank match of the responses and the questionnaires Table 10. The key findings of discussion with experts are summarised as below:

a. Crotch length of trousers seemed shorter than the body measurement size.

b. Hip length of subjects was longer than the standard torso.

c. Side seam around the pelvis area had an unnecessary ease to cause creasing.

d. Hip area had too much ease for the subject's hip size.

e. Waist line was highly positioned than nowadays lower-waisted trousers

In general, unsatisfactory appearance and fit were generated from shorter crotch and hip lengths in pattern making methods. It was found that the uniformly fixed suggestion of crotch and hip lengths calculated by height proportion were not suitable to the subject. Unnecessary ease around the side seam and hip at the experimental trousers are represented that the consideration of curved body shape should be required. Also, it is inferred that the body characteristics between Asian and Western women should be considered. Asian women normally have a longer crotch and shorter leg in comparison with Western women. Therefore, the chosen three pattern making methods developed in Western countries could not be adapted properly to the Asian subject. As to aesthetic perspective, waist line was examined rather high, but this is referred that the experimental trousers were constructed as the basic pattern block to modify into different waistlevelled trousers. Regarding an opinion about clothing fit, it is found that tight-fitted trousers are preferred as to be comfortable and good looking. Also, fabric property is found as a considerable factor because tight-fitted trousers made by well-starched fabric might be

Table 9 Result of upright posture examination by experts more comfortable than wide-fit trousers made of thick fabric.

Subject evaluation: Tables 11 shows the results of the evaluation from the subject. Overall, the four experimental trousers were generally examined as comfortable and significant differences were not found at crotch, thigh, and calf area. However, there was a slight increase in dissatisfaction when the subject changed poses, and the amount of discomfort increased from Movement 1 (standing) to Movement 5 (squatting). Overall, the subject evaluated the Bunka method as the highest and ESMOD as the lowest. This inferred that the crotch length size in Bunka method was close to the subject's crotch length, and it is also the longest among the four pattern making methods. The key findings of discussion with the subject are followed as below.

i. Ease of each part was generally sufficient to give a comfortable feeling except for the tight waist.

ii. Unnecessary ease was found at the side and back of the hip in particular between hip and thigh at the back.

iii. The width of the trousers was too broad.

iv. Waist line was positioned higher than the trousers normally worn

The subject evaluated the waist area as tighter than the other parts, and it was found that ease amounts around hip and side were too much. This influenced the subject to feel that the overall silhouette was shaped inadequately and the trousers could not cover the hips properly. The width of the trousers was evaluated overly broad, and it is inferred that the flapping leg area of the trousers gave discomfort to the subject. As same as the experts' opinion, the subject also mentioned that the waist line position of the trousers was higher than her normal trousers.

\begin{tabular}{llllll}
\hline \multicolumn{1}{c}{ Aldrich } & Armstrong & Bunka & ESMOD & F \\
\hline (1) Front & $3.70 \mathrm{~A}(.26)$ & $3.72 \mathrm{~A}(.23)$ & $3.47 \mathrm{~A}(.32)$ & $3.18 \mathrm{~B}(.35)$ & $7.42^{* * * *}$ \\
(2) Side & $3.83(.40)$ & $3.92(.39)$ & $3.85(.23)$ & $3.49(.22)$ & 1.44 \\
(3) Back & $3.86 \mathrm{~A}(.23)$ & $3.70 \mathrm{~A}(.18)$ & $3.62 \mathrm{~A}(.19)$ & $3.12 \mathrm{~B}(.45)$ & $12.74 * * *$ \\
\hline
\end{tabular}

$* * * \mathrm{p}<.001$

Table 10 Result of movement examination by experts

\begin{tabular}{llllll}
\hline Ranking & Movement I & Movement 2 & Movement 3 & Movement 4 & Movement 5 \\
\hline I & ESMOD & Aldrich & Aldrich & Aldrich & Bunka \\
2 & Bunka & Bunka & Bunka & Bunka & Aldrich \\
3 & Armstrong & ESMOD & ESMOD & Armstrong & ESMOD \\
4 & Aldrich & Armstrong & Armstrong & ESMOD & Armstrong \\
W & 0.03 & 0.52 & 0.07 & 0.14 & 0.09 \\
p-value & $.68^{* *}$ & 0 & $.31^{*}$ & $.07^{*}$ & $.21^{*}$ \\
\hline
\end{tabular}

Table I I Result of examination by subject

\begin{tabular}{llllllll}
\hline & $\begin{array}{l}\text { Upright } \\
\text { posture }\end{array}$ & Movement I & Movement 2 & Movement 3 & Movement 4 & Movement 5 & Mean \\
\hline Aldrich & 5 & 5 & 4.57 & 4.57 & 5 & 4.57 & 4.79 \\
Armstrong & 5 & 4.85 & 4.28 & 4.57 & 5 & 4.28 & 4.66 \\
Bunka & 5 & 5 & 4.85 & 5 & 5 & 4.85 & 4.95 \\
ESMOD & 4.42 & 4.85 & 4.14 & 4.28 & 4.28 & 4 & 4.33 \\
\hline
\end{tabular}




\begin{tabular}{|l|l|l|}
\hline Hip length & Body Rise & Crotch Length \\
\hline
\end{tabular}

Figure 4 Measurement methods of hip length, body rise, and crotch length.

\section{Conclusion}

This study compared different trouser pattern making methods through the basic pattern block developments, wearer testing experiment, and experts' sensory test with discussion. The suitability and applicability onto the specific body size and type of subject were analyzed. From the results mentioned in the previous section, significant findings can be drawn from this study as follows.

First, the subject body measurement sizes were greater than the average body size, and body type is not classified into the average division. It is inferred that consideration of specific body types outside of the average is required.

Second, theoretical construction methods of four trouser basic patterns were not significantly different. However, the slight differences of construction method and suggested amount of ease influenced the clothing fit and overall shape.

Third, as to the results of the evaluation from the questionnaire, experts evaluated the Armstrong method as the best and Aldrich was chosen when movability was tested. However, Bunka was found also suitable during discussion, and it was the same with the subject's choice.

Overall, it is inferred that only following one certain method is not the best answer and it is difficult to generate only one pattern making method to fit a specific subject. The four pattern making methods studied were all developed before the technology became available to provide the accurate body size and shape data when have today. It is therefore suggested that the time may be right for a new pattern making method to be developed. Moreover, a deeper understanding of body shape and size in different ages and ethnicity should be gained to develop an optimum pattern without wasting time to modify and to satisfy the majority of customers.

There were some limitations which influenced the overall results of the study. First, the definition of clothing comfort, fit preference, and good appearance are subjective and differ between individuals and therefore pre-training of evaluators may improve consistency. Second, the number of experts who participated in the fit evaluation was insufficient to generalize even though the statistical analyses were verified. Further research can consider the comparison of diverse body types or characteristics to be adopted for different clothing types. It is also suggested that, when choosing and analysing subjects for comparison, significant consideration be given to body shapes and sizes. In order to increase the reliability of the results of questionnaires, it is recommended that more participants are collected for the survey.

\section{Acknowledgments}

None.

\section{Conflict of interest}

Author declares there is no conflict of interest in publishing the article.

\section{References}

1. Glock RE, Kunz GI. Apparel Manufacturing: Sewn Product Analysis. 4th ed. Pearson Education. USA; 1995.

2. Kang SH, Suh MA. Clothing construction-Theory and Practice. Kyomunsa. Seoul, Korea; 2003.

3. Kang WB. A Study of Block Pattern Utilized by Women's Apparel Manufacturers-Focusing on Slacks Pattern for Women in their 20s 30s. Department of Communication in Fashion Industry. Masters dissertation. The Graduate School of Human Environmental Science. Yeonsei University, Seoul, Korea; 2004.

4. Chun JS. The Basic of Pattern Construction. Suhaksa. Seoul, Korea; 1998.

5. Hudson PB. Guide to apparel manufacturing. Med apparel Inc, Greenboro, North Carolina, USA; 1989.

6. Fischer A. Basics fashion design 03: Construction. Bloomsbury publishing. UK; 2008.

7. Ashdown SP, Loker S, Schoenfelder K, et al. Using 3D scans for analysis. J Text \& Apparel, Technology \& Management. 2004;4(1):1-12.

8. Alexander M, Connell LJ, Presley AB. Clothing fit preferences of young female adult consumers. Inter $J$ Clothing Sci \& Technol. 2005;17(1):52-64.

9. Bye EK, Delong MR. A visual sensory evaluation of the results of two pattern grading methods. Clothing \& Text Res J. 1994;12(4):1-7.

10. Suk EY, Kim HK. A study on the automatic drafting of basic slacks pattern for young men. J Korean Society of Clothing \& Textiles. 1996;20(1):54-65.

11. Kam W-Y. A study of pattern development for women's low-waisted slack design. Masters Dissertation, Ulsan University, Korea; 2005.

12. Oxford Dictionary. 'Oxford Dictionaries our story, products, technology, and news'. Oxford Dictionary Press. 2016.

13. Armstrong HJ. Patternmaking for fashion design. 5th ed. Pearson Education, USA; 2009.

14. Aldrich W. Metric pattern cutting for women's wear. 5th ed. UK: Wiley-Blackwell; 2008.

15. Kim KH. A Study on the Basic Slacks Pattern for the Obese Elderly Women's-Based on their Lower Body Type Analysis. Department of Clothing and Textiles, Graduated School of Konkuk University. Master dissertation, Seoul, Korea; 2001.

16. Hwang SE. A Study on the Development Basic Slacks Pattern of Abdominal Obesity Women. Department of Clothing \& Textiles Graduate School of Ewha Womans University. Master dissertation, Seoul, Korea; 2007.

17. Lee JS, Lee JR. The Development of Pants Pattern for the Improvement of Obese Women's Fit. J Korean Society for Clothing Industry. $2011 ; 13(2): 253-262$

18. Lee DY. Developments of Slacks Pattern for Peculiar Lower Body type: Focused on Females in their Twenties. Department of Clothing \& Textiles, Graduate School of Konkuk University. Master dissertation, Seoul, Korea; 2017

19. Byun JH. The Development of the Jeans Pattern for Plus-sized Women in the 20's. Department of Clothing and Textiles, The Graduate School of Hanyang University. Master dissertation, Seoul, Korea; 2010. 
20. Lee JJ. A Study of Knit Slacks Pattern according to Lower Body Types of Middle-aged Women. Department of Clothing and Textiles, The Graduate School of Hanyang University. Master dissertation, Seoul, Korea; 2011.

21. Bunka Fashion College. Bunka fashion series garment design textbook 3-Skirts and Pants, Seoul, Korea; 2010.

22. ESMOD. Women's garment 2-Become a pattern drafter series. ESMOD Editions. 2009.
23. NHS. BMI health weight calculator. 2016.

24. Size Korea. Size Korea; 2016.

25. McCormack H. The shape of things to wear: scientists identify how women's figures have changed in 50 years. 2005 .

26. Na MH, Kim JH, Yun JK. Industrial Pattern CAD-using Cyber CAD pattern system. Kyohak research academy. Seoul, Korea; 2009.

27. Kim KH, Kim MY, Kim SY, et al. Western garment construction 2. Seoul: Sung shin women's university publisher; 2009. 